\title{
Blanket Module Boil-Off Times during a Loss-of-Coolant Accident - Case 0: with Beam Shutdown only
}

by

L. L. Hamm

Westinghouse Savannah River Company

Savannah River Site

Aiken, South Carolina 29808

S. Y. Lee

M. A. Shadday

F. G. Smith, III

A document prepared for SENDING TO LANL at , , from - .

DOE Contract No. DE-AC09-96SR18500

This paper was prepared in connection with work done under the above contract number with the U.S.

Department of Energy. By acceptance of this paper, the publisher and/or recipient acknowledges the U.S. Government's right to retain a nonexclusive, royalty-free license in and to any copyright covering this paper, along with the right to reproduce and to authorize others to reproduce all or part of the copyrighted paper. 


\title{
BLANKET MODULE BOÍL-OFF TIMES DURING A LOSS-OF-COOLANT ACCIDENT (LOCA) -
}

Case 0: with Beam Shutdown only

\author{
L. Larry Hamm \\ Si Young Lee \\ M. Andy Shadday \\ Frank G Smith III
}

Westinghouse Savannah River Company

Savannàh River Site

Aiken, SC ' 29808'
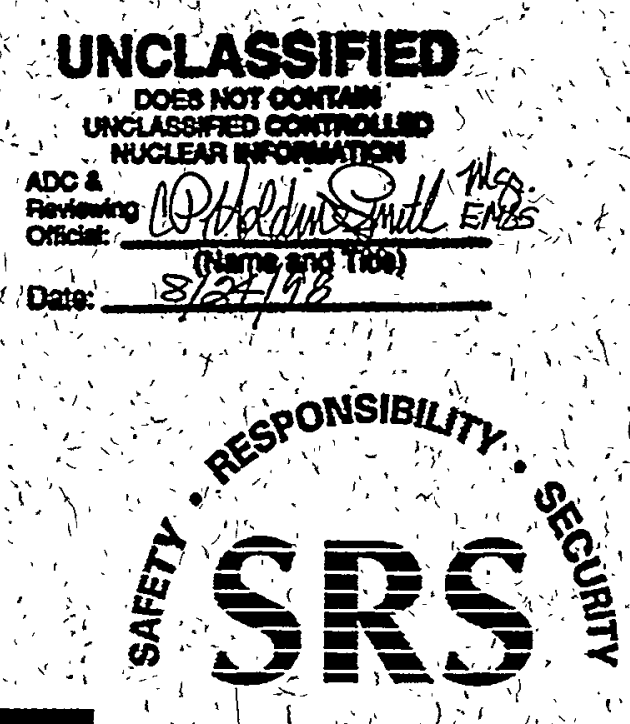

SAVANNAH RIVER SITE 


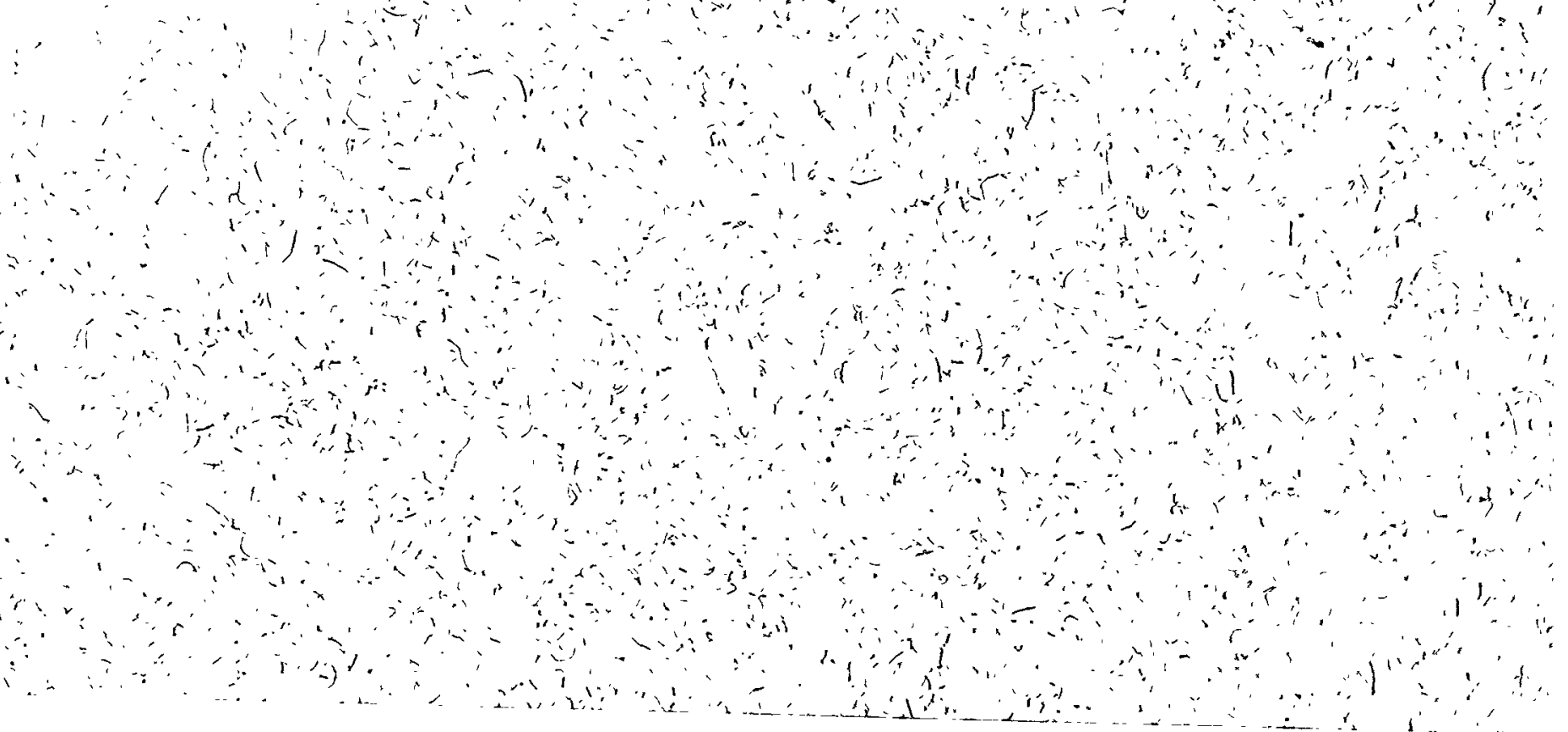

\section{DISCLAIMER}

This report was prepared as an account of work sponsored by an agency of the United States Government. Neither the United States Government nor any agency thereof, nor any of their employees, makes any warranty, express or implied, or assumes any legal liability or responsibility for the accuracy, completeness, or usefulness of any information, apparatus, product, or process disclosed, or represents that its use would not infringe privately owned rights. Reference herein to any specific commercial product, process, or service by trade name, trademark, manufacturer, or otherwise does not necessarily constitute or imply its endorsement, recommendation, or favoring by the United States Government or any agency thereof. The views and opinions of authors expressed herein do not necessarily state or reflect those of the United States Government or any agency thereof.

This report has been reproduced directly from the best available copy.

Available to DOE and DOE contractors from the Office of Scientific and Technical Information, P.O. Box 62, Oak Ridge, TN 37831; prices available from (615) 576-8401. Available to the public from the National Technical Information Service, U.S. Department of
Commerce, 5285 Port Royal Road, Springfield, VA 22161 . 


\section{DISCLAIMER}

Portions of this document may be illegible in electronic image products. Images are produced from the best available original document. 
KEYWORDS:

Accelerator Production of Tritium

Blanket System

Conceptual Design

System Model

Boil-off Model

Safety Analysis

RETENTION - Permanent

\section{BLANKET MODULE BOIL-OFF TIMES DURING A LOSS-OF-COOLANT ACCIDENT (LOCA) -}

\section{Case 0: with Beam Shutdown only}

SAVANNAH RIVER TECHNOLOGY CENTER

L. Larry Hamm

Si Young Lee

M. Andy Shadday

Frank G. Smith, III

Publication Date: July, 1998

Westinghouse Savannah River Company

Savannah River Site

Aiken, SC 29808

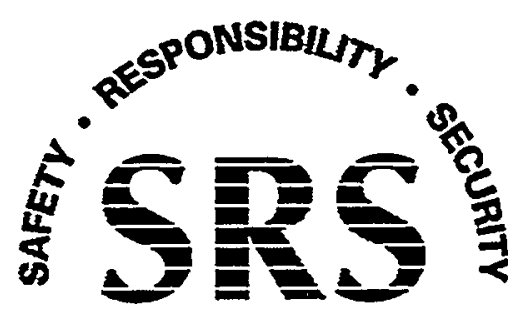

SAVANNAH RIVER SITE

Prepared for the U.S. Department of Energy under Contract No. DE-AC09-96SR18500 


\section{DOCUMENT: WSRC-TR-98-00213}

TITLE: BLANKET MODULE BOIL-OFF TIMES DURING A LOSSOF-COOLANT ACCIDENT (LOCA) - Case 0: with Beam Shutdown only

\section{APPROVALS}

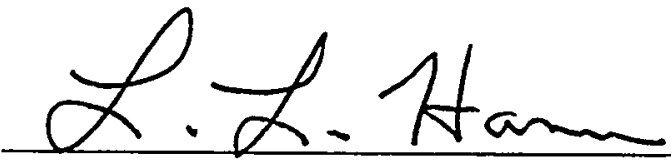

Date: $7-16-98$

L. Larry Hamm, Task Leader (EM\&S Group/SRTC)

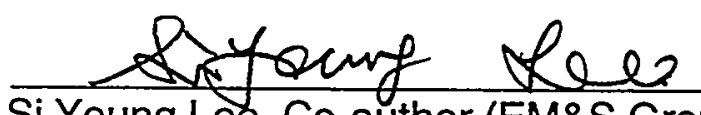

Si Young Lee, Co-author (EM\&S Group/SRTC)

Date: $7-20-98$

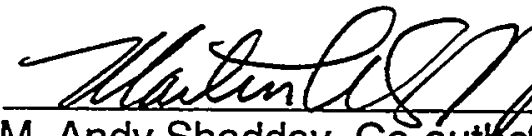

M. Andy Shadday, Co-authof (EM\&S Group/SRTC)

Date: $7 / 20 / 98$

Znank 1 lmeth 4

Frank G. Smith, III, Co-author (PC\&C Group/SRTC)

Date: $2 / 20 / 98$

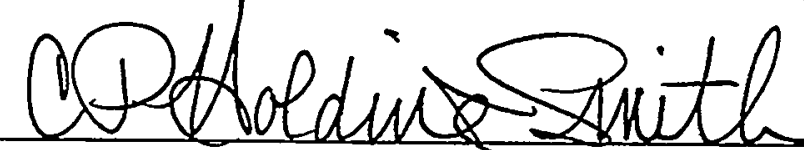

Cynthia P. Holding-Smith,

Date:

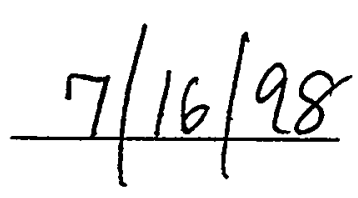

m.G. QOra

Martha A. Ebra, Manager (EDS/SRTC)

Date: $\frac{280098}{0490}$

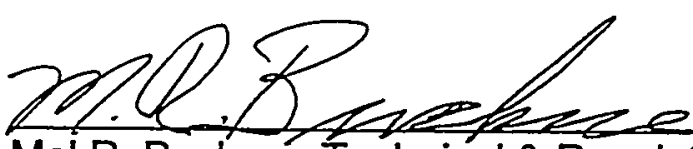

Mel R. Buckner, Technical \& Regulatory Lead (APT OPO)

The internal technical review function is being performed at the APT project level and is coordinated through LANL. . 


\section{Table of Contents}

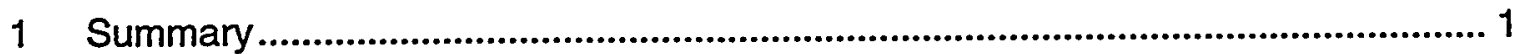

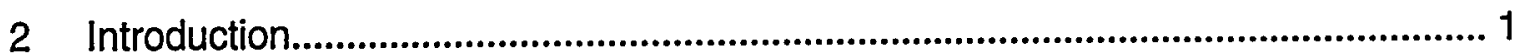

3 Solution Approach and Methodology …............................................................... 4

4 Evaluation Model Results and Discussions......................................................... 9

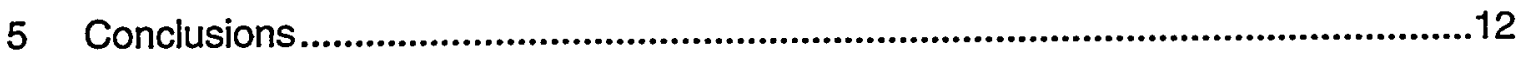

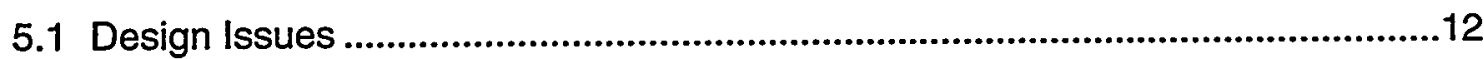

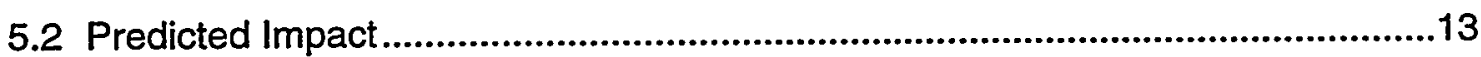

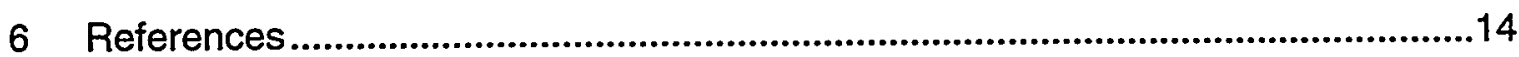

Appendix A: Software Specifications for BOIL Code ...................................................A1

Appendix B: Sample Input Deck ........................................................................... B1

Appendix C: Code Listing .............................................................................................. C1 


\section{List of Figures}

Figure 2-1 Decay heat power fractions for various types of blanket modules...........2

Figure 2-2 Cross-sectional facemap of six-lumped blanket system module

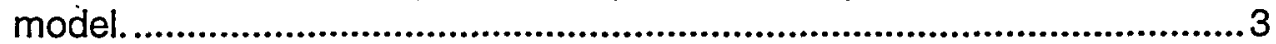

Figure 3-1 A schematic of an isolated module loop (Module 1) used in the

Figure 3-2 $\quad$ Deposited power profiles used in the TRAC system and EM models. ............................................................................................99

Figure 4-1 Module 1 estimated coolant liquid level as a function of time based on the EM.............................................................................. 11

Figure 4-2 Module 1 estimated maximum aluminum temperature as a function of time based on the EM.

Figure 4-3 Module 1 estimated boil-off rate as a function of time based on the EM.

\section{List of Tables}

Table 2-1 Key parameters associated with each composite module of the six lumped blanket module system model. ...................................................... 4

Table 3-1 Deposited power and available liquid mass for each lumped blanket module. .5

Table 4-1 Times to reach boiling and initial dry-out for the six lumped blanket modules. 


\section{Summary}

A conservative evaluation model (EM) approach is used to analyze accident scenarios with significant coolant inventory losses during Large Break Loss-of-Coolant Accidents (LBLOCAs) external to the cavity vessel, where only the beam power is shut down and no other mitigation actions are taken. The EM is a simplified modeling approach that performs a bounding analysis. Material design criteria have been established for each blanket module to ensure that coolable geometries are maintained. Without corrective measures, it has been conservatively determined that peak metal temperatures would not exceed these design criteria until at least 28 hours after beam shutdown. This time duration is sufficiently long that it is reasonable to assume that additional measures can be implemented, such as:

- Restoring the availability of one of the Residual Heat Removal (RHR) systems;

- Restoring the availability of the cavity flood system; or

- Replenishing liquid coolant inventory that is boiled off using purification lines (initially about $0.25 \mathrm{gpm}$ would be required with demand decreasing as the residual deposited power decays).

\section{Introduction}

This report is one of a series of reports that document LBLOCA analyses for the Accelerator Production of Tritium (APT) primary blanket Heat Removal (HR) system [16]. These analyses were performed for Revision 0 of the Preliminary Safety Analysis Report (PSAR). This report documents the analysis results of a LBLOCA where the accelerator beam is shut off without primary pump trips and neither the RHR nor the cavity flood systems operate.

For the set of LOCA break locations examined, it is assumed that the trip signal to shutdown the accelerator beam is initiated based on a $5 \%$ reduction in pressurizer surge-line pressure. Signal detection occurs within hundredths of a second following the initiating event. The trip signal is activated approximately 0.01 seconds after the initiating event occurs. A conservative 0.2 second time delay to account for signal processing is assumed (best estimate values range from 0.1 to 0.2 second delays) so that the actual beam shutdown begins approximately 0.21 second after the initiating event occurs. After the APT beam system shutdown, blanket deposited power drops rapidly. Figure 2-1 shows transient decay power after shutdown as a fraction of steadystate power for the $1700 \mathrm{MeV}$ APT design with 13 tungsten ladders [7]. For example, power levels are approximately 1 to $3 \%$ of their pre-shutdown levels within 1 second.

Trip signals for the primary HR pump are based on the same logic as for a beam shutdown. For this set of LOCA break location scenarios it is assumed that the primary HR pumps fail to trip. Also, the primary RHR pumps and the cavity flood system are assumed to be inoperable. The likelihood of not having either the RHR or cavity flood systems available upon demand is extremely unlikely. Therefore, for each break location, this event sequence is in the Beyond Extremely Unlikely (BEU) frequency range. After a beam shutdown, none of the other available accident mitigation options are activated. The geometric configuration of the external piping for the primary HR 
system, in relation to the fixed headers, has been designed such that any external large break would eventually break seal and would not continue to draw coolant inventory out of the blanket modules and their fixed headers.

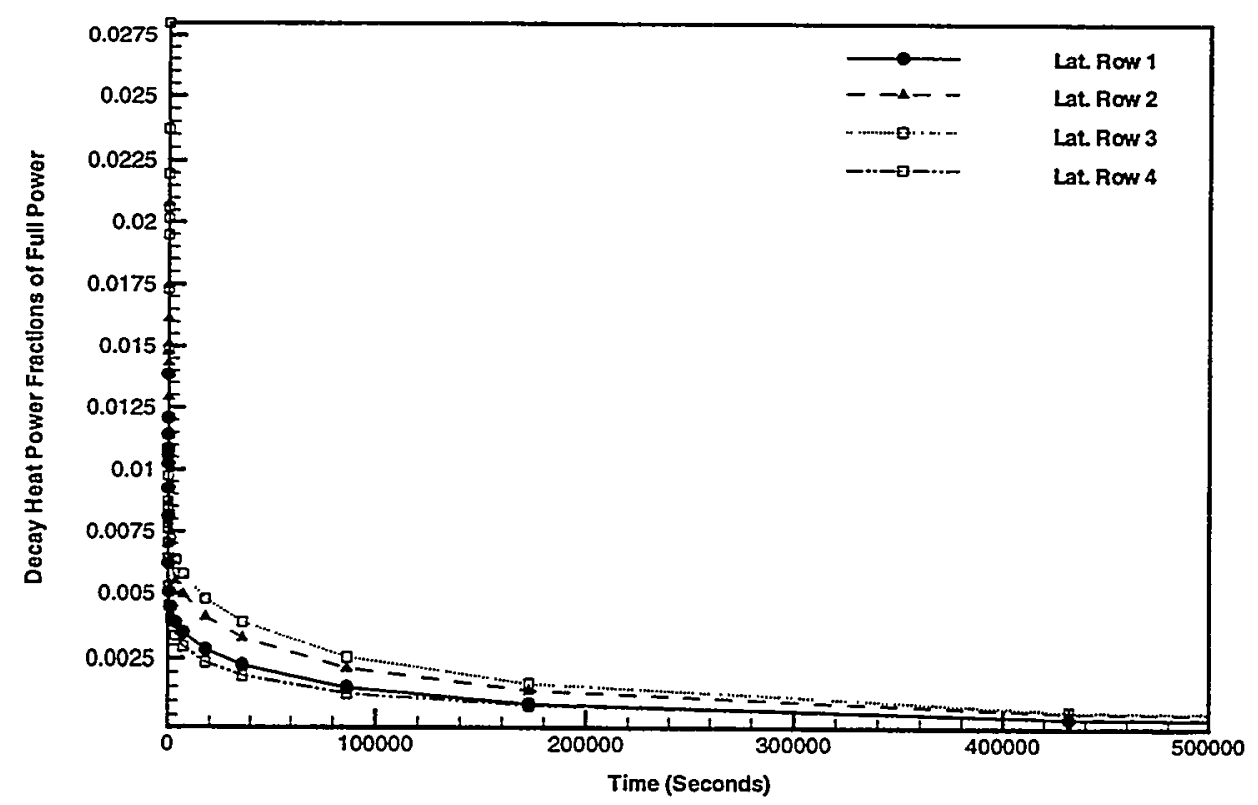

Figure 2-1 Decay heat power fractions for various types of blanket modules.

The unmitigated accident analyses were performed using an EM based on an overall thermal energy balance to model transient behavior for the blanket modules. The EM consists of calculations to estimate the time it would take the APT blanket module to heat to boiling under adiabatic heat up conditions. The masses of lead, aluminum and water in the entire blanket module, and the mass of water in portions of the primary HR loop, were estimated using data from the TRAC system model [7]. Individual deposited power profiles were used to estimate the deposited power to each module during the transient.

The current APT blanket system consists of 16 unique blanket modules. Each module is separately connected to the two fixed coolant headers. A lumping strategy was developed based on module similarity, deposited power levels, and locations that resulted in a total of six separate lumped modules that significantly reduced system computational requirements. Figure 2-2 shows a cross-sectional facemap for the sixmodule blanket system. Table 2-1 summarizes the module description, thermal deposited power, and connection pipe size for each of the six blanket modules as modeled in the one-dimensional lumped approach. Detailed TRAC system model descriptions are provided in Ref. [7]. Results from a single long term TRAC system calculation were used to analyze the loss-of-flow accident and to provide starting conditions for the EM. The transient behavior of the six lumped blanket modules were then predicted using as the initial conditions the results from the integrated system model 950 seconds into an external LBLOCA. 


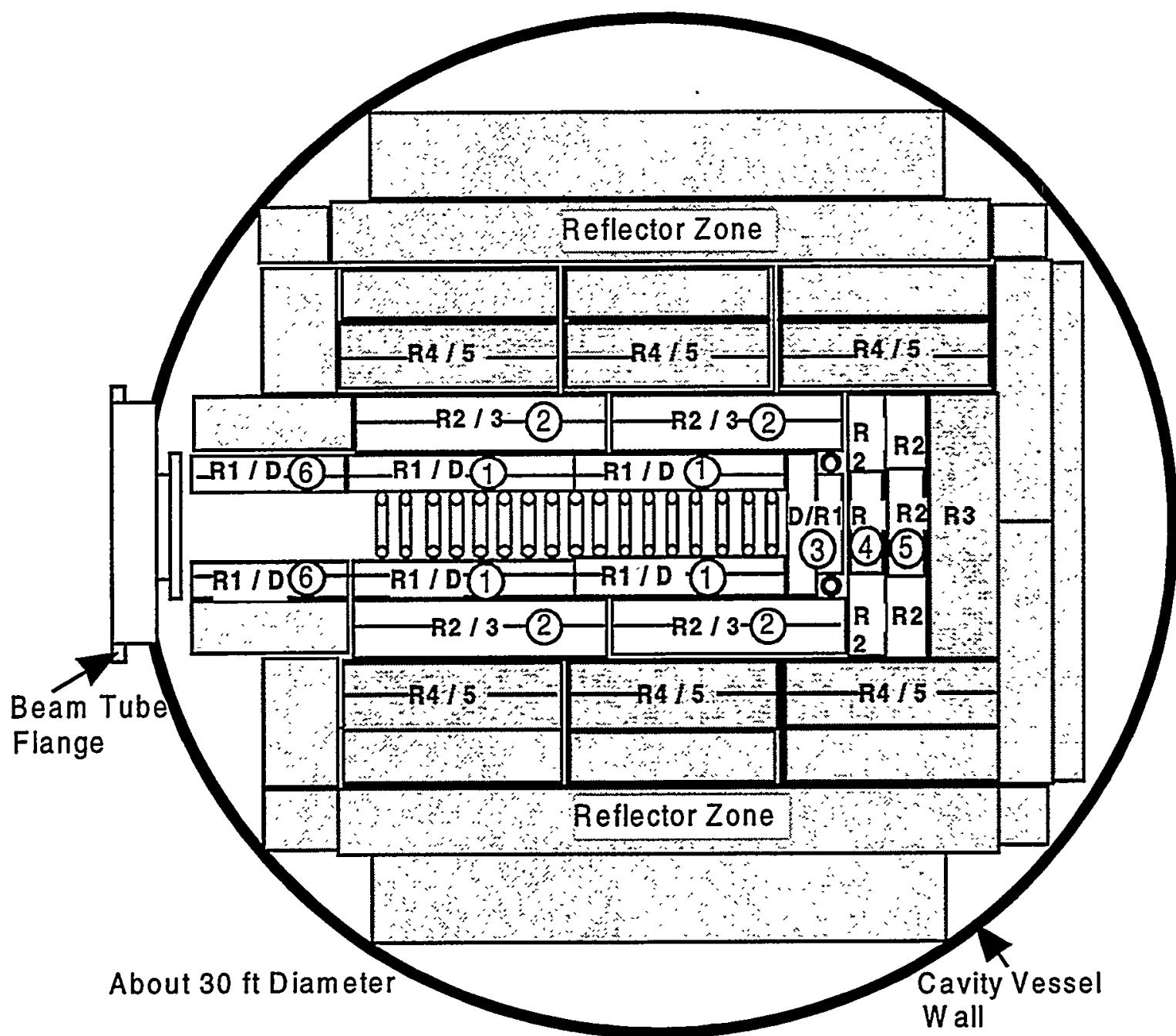

(6) Snout, 4 Bottom Modules, and 2 Top Modules

Figure 2-2 Cross-sectional facemap of six-lumped blanket system module model. 
Table 2-1 Key parameters associated with each composite module of the six lumped blanket module system model.

\begin{tabular}{|c|c|c|c|}
\hline Moduile & Corresponding Protôtypic 16 Full & $\begin{array}{l}\text { Deposited Power } \\
\text { Downflowiluptowl } \\
\text { Total Power }\end{array}$ & $\begin{array}{l}\text { Pipe } \\
\text { Size } \\
\text { (inch) }\end{array}$ \\
\hline 1 & $\begin{array}{c}\text { Front } 1^{\text {st }} \text { Lateral Decoupler / } \\
\text { Row } 1 \text { Module } \\
\text { Back } 1^{\text {st }} \text { Lateral Decoupler / } \\
\text { Row } 1 \text { Module }\end{array}$ & $\begin{array}{c}8.222 / 15.768 / \\
23.990\end{array}$ & 7.500 \\
\hline 2 & $\begin{array}{c}\text { Front } 2^{\text {nd }} \text { Lateral Row } 2 / \\
\text { Row } 3 \text { Modules } \\
\text { Back } 2^{\text {nd }} \text { Lateral Row } 2 / \\
\text { Row } 3 \text { Modules }\end{array}$ & $3.060 / 7.660 / 10.720$ & 4.750 \\
\hline 3 & $\begin{array}{c}1^{\text {st }} \text { Downstream Decoupler / } \\
\text { Row } 1 \text { Module }\end{array}$ & $0.744 / 2.812 / 3.556$ & 3.750 \\
\hline 4 & $\begin{array}{l}2^{\text {nd }} \text { Downstream Row } 1 / \\
\text { Row } 2 \text { Module }\end{array}$ & $3.924 / 5.412 / 9.336$ & 5.375 \\
\hline 5 & $\begin{array}{l}3^{\text {rd }} \text { Downstream Row } 2 / \\
\text { Row } 2 \text { Module }\end{array}$ & $1.355 / 1.811 / 3.166$ & 6.000 \\
\hline 6 & $\begin{array}{c}\text { Low Power Modules } \\
\text { Blanket Upstream Dec. / } \\
\text { Row } 2 \text { Module } \\
\text { Lower Front Decoupler / Row } 2 \text { Module } \\
\text { Lower Front Row } 2 \text { / Row } 2 \text { Module } \\
\text { Lower Back Decoupler / Row } 2 \text { Module } \\
\text { Lower Back Row } 2 \text { / Row } 2 \text { Module } \\
\text { Upper Front Row } 2 \text { / Row } 2 \text { Module } \\
\text { Upper Back Row } 2 \text { / Row } 2 \text { Module }\end{array}$ & $\begin{array}{c}\text { (Horizontal Flow) } \\
0.0 / 5.712 / 5.712\end{array}$ & 3.875 \\
\hline $\begin{array}{l}\text { Total } \\
\text { Deposited } \\
\text { Power }\end{array}$ & - & $\begin{array}{c}17.305 / 39.175 / \\
56.480\end{array}$ & - \\
\hline
\end{tabular}

\section{Solution Approach and Methodology}

The solution strategy chosen is based on the realization that simulation times on the order of days are unattainable using the integrated system model and that a simplified bounding analysis is preferred when such analyses provide acceptable results. A simplified conservative evaluation model based on a lumped overall energy balance was used to analyze accident scenarios with significant loss of coolant water inventory, where only the beam power is shutdown and no other mitigation actions are taken. The transient behavior of individual blanket modules was predicted using as initial conditions results from the integrated system model 950 seconds into an external LBLOCA (see Ref. 2). At this point in time after a large break initiating event, the system behavior (i.e., blanket module and HR coolant loop temperatures) is essentially the same regardless of break location. Therefore, the EM results are valid for the entire set of break locations considered. 
The EM approach conservatively assumes that beyond 950 seconds the pressurizer inventory has been depleted and external loop flow to and from the fixed headers has ceased. Beyond this point, since all potential external break locations are above the fixed inlet headers, no additional loss of coolant inventory due to siphoning will occur. At 950 seconds we also no longer take credit for any water remaining in the loops beyond the fixed headers including the inventory within the fixed headers themselves. Water inventory within each module unit is assumed to be completely isolated from its neighboring modules. No liquid inventory draining in from the HR, RHR, or pressurizer external piping is accounted for in the analysis.

The most limiting module corresponds to the one that takes the minimum time, $t^{*}{ }_{\mathrm{min}}$, to deplete the water inventory between the fixed headers and the top of the module under unmitigated LBLOCA conditions. That is,

$$
t_{\min }^{*}=\min _{i=106}\left\{t_{\bmod u l e ~}^{*}\right\}
$$

Beyond this point in time, the module begins to uncover exposing the metal surfaces. Table 3-1 lists the pre-incident deposited thermal power, the total cooling water inventory (including the water within the module itself), and the water inventory above the heated section of the module for all six blanket modules as modeled in the TRAC system model. The shape of the deposited power decay curve and the water inventory between the top of the module and the fixed header, as well as the total water inventory, will determine the limiting module. Therefore, although Module 1 with the largest deposited power did eventually turn out to be the limiting module this was not immediately clear and all six of the lumped modules were subjected to the transient EM analysis to determine the worst case. Figure 3-1 shows the geometrical arrangement for Module 1 as it was used in the present analysis.

Table 3-1 Deposited power and available liquid mass for each lumped blanket module.

\begin{tabular}{|c|c|c|c|}
\hline $\begin{array}{l}\text { Lumped } \\
\text { Module }\end{array}$ & $\begin{array}{l}\text { Deposited } \\
\text { Power } \\
\text { (MW) }\end{array}$ & $\begin{array}{l}\text { Total Water } \\
\text { Mass in Module } \\
\text { (kg) }\end{array}$ & $\begin{array}{l}\text { Water Mass } \\
\text { Above Module } \\
\text { (kg) }\end{array}$ \\
\hline 1 & 23.99 & 3707.9 & 2033.5 \\
\hline 2 & 10.72 & 3804.0 & 1590.1 \\
\hline 3 & 3.556 & 1700.3 & 1089.1 \\
\hline 4 & 9.336 & 2084.5 & 1224.7 \\
\hline 5 & 3.167 & 2171.0 & 1289.7 \\
\hline 6 & 5.712 & 3784.8 & 2444.4 \\
\hline
\end{tabular}

Note: * total water inventory mass for each lumped blanket module loop from the supply fixed header to the return fixed header

In the first phase of the EM approach, an adiabatic sensible heat-up calculation is performed to determine the time required to reach saturation conditions, corresponding to the system pressure at the mid-plane, within the heated sections of each module. These calculations take credit for the thermal capacitance of the metal and the water residing within the blanket modules along with the water contained within the module plenums (i.e., inlet, middle, and outlet plenums) and inlet/outlet piping attached to the 
fixed headers (excluding inventory within the fixed headers themselves). Each module is materially and thermally isolated from its surrounding structures once the coolant water has drained below the fixed headers. During the second phase of the EM approach, boil-off calculations are performed based on the latent heat of vaporization of light water until the level of water remaining within a given module loop reaches the top of the module unit's heated section. No credit is taken for condensation/reflux due to cold surfaces above each blanket module.

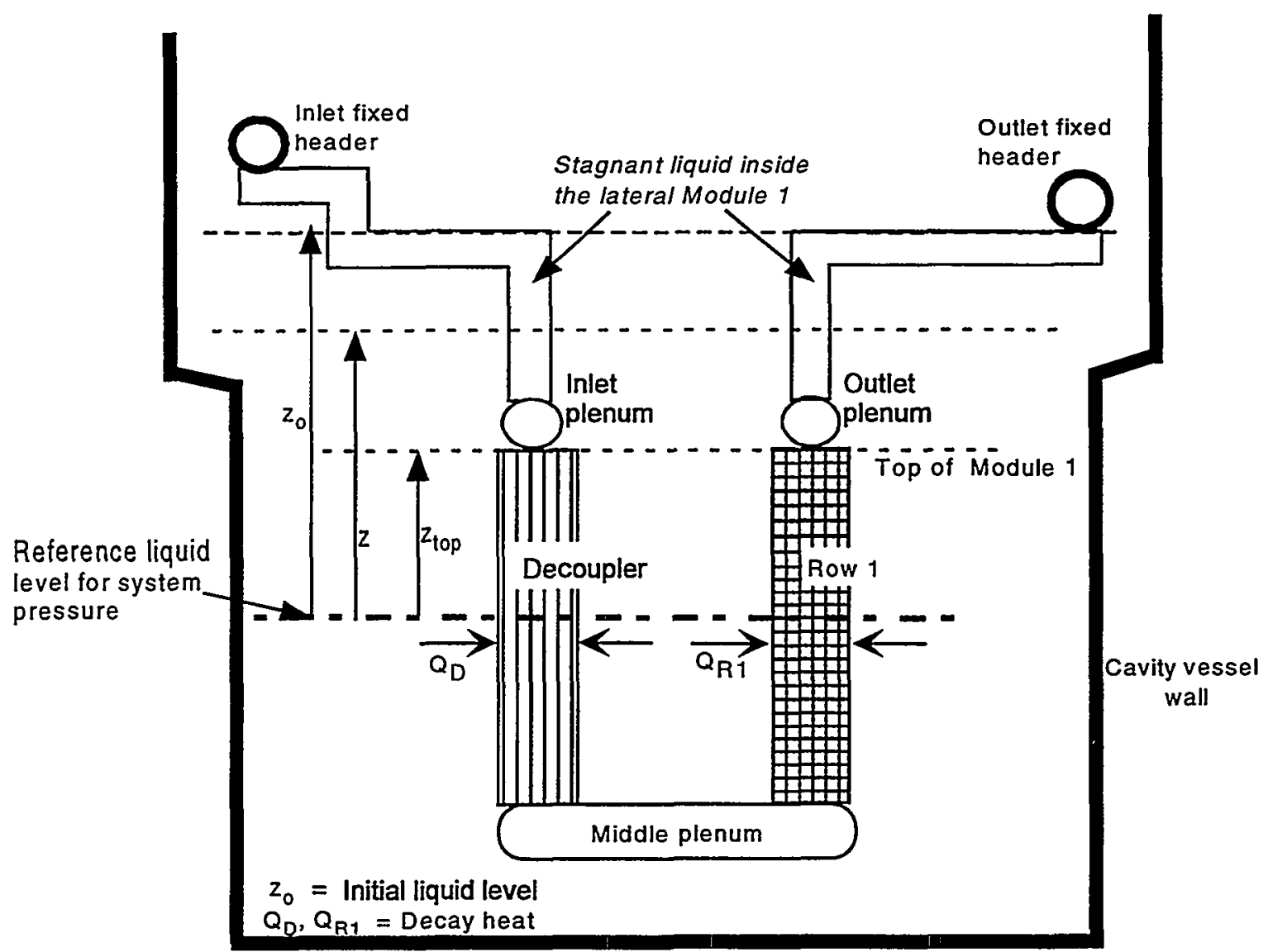

Figure 3-1 A schematic of an isolated module loop (Module 1) used in the. EM analysis.

Limited preliminary FLOWTRAN-TF bin analyses have been performed to investigate the heat removal capability of the long narrow discrete channels under partially filled conditions. Beyond the EM calculations, preliminary FLOWTRAN-TF results indicate that acceptable metal temperatures are maintained for channels partially filled with water. However, at some reduced liquid level the onset of a thermal excursion (OTE) is expected to occur. For these analyses we conservatively assumed that a thermal excursion would occur once the tops of the heated sections are reached.

The EM approach uses the following governing equations for adiabatic heat-up (nonboiling) and boil-off situations based on the assumption of thermal equilibrium. Using the notation shown in Fig. 3-1, total thermal energy input $\left(Q_{T}\right)$ to the module unit (Module 1 is used as an example) is calculated as: 


$$
Q_{T}=Q_{D}+Q_{R 1}
$$

In Eq. (2) $Q_{D}$ is the thermal power deposited in the decoupler leg, while $Q_{R 1}$ is the thermal power deposited in the blanket Row-1 leg. Calculation of the liquid mass balance is performed using:

$$
\frac{d m_{f}}{d t}= \begin{cases}0 & \text { for non }- \text { boiling system } \\ -\dot{m}_{g} & \text { for boiling system }\end{cases}
$$

In Eq. (3) $\dot{m}_{g}$ is the boil-off rate due to the phase change of light water.

During the time periods of interest, decay heat levels are generally quite low and temperature differences between the fluid and its neighboring heated metal structures will be small. Therefore, near thermal equilibrium is assumed for the fluid and solid composite (i.e., $T=T_{s}=T_{f}$ ) during both sensible heat-up and boil-off conditions. A thermal energy balance for an entire module structure (including fluid and soild components) becomes:

$$
\left(m_{s} C_{p s}+m_{f} C_{p f}\right) \frac{d T}{d t}=\left\{\begin{array}{cc}
Q_{T} & \text { for sensible heatup } \\
Q_{T}-\dot{m}_{g} h_{f g} & \text { for boil - off }
\end{array}\right.
$$

In Eq. (4), $m_{s}$ and $m_{f}$ are the metal structure and total fluid mass within a given of module unit, respectively. $C_{p s}$ and $C_{p f}$ are constant pressure specific heats of the metal structure and fluid, respectively. $h_{f g}$ is the latent heat of evaporation. The boil-off rate $\left(\dot{m}_{g}\right)$ in Eq. $(4)$ is zero for the non-boiling situation. The system pressure $(P)$ is calculated in terms of liquid height $(z)$ and liquid density $\left(\rho_{f}\right)$ assuming static equilibrium conditions from the equation:

$$
P=P_{a r m}+\rho_{f} g z
$$

In Eq. (5), $z$ is the liquid level height with respect to the center of a blanket module as shown in Fig. 3-1, while $P_{\text {arm }}$ and $g$ are atmospheric pressure and gravitational acceleration, respectively. For modeling convenience the center of the blanket modules is set as our reference elevation. Once fluid saturation conditions are met, bulk boiling is initiated and the transient composite temperature $(T)$ is set equal to the saturation temperature $\left(T_{s a t}\right)$ corresponding to the system pressure $(P)$ predicted by Eq. (5). The saturation temperature $\left(T_{s a t}\right)$ is determined by an equation of state for light water:

$$
T=T_{\text {sat }}(P) \quad \text { (during boiling) }
$$

The gradient in saturation temperature with respect to system pressure can be expressed in terms of the rate of change in liquid level as (making use of Eqs. (5) and (6)):

$$
\frac{d T}{d t}=\left(\frac{d T_{s a t}}{d P}\right)\left(\frac{d P}{d t}\right)=\rho_{f} g\left(\frac{d T_{s a t}}{d P}\right)\left(\frac{d z}{d t}\right)
$$


The rate of liquid level change in Eq. (7) can be expressed in terms of the boil-off rate $\left(\dot{m}_{g}\right)$ under bulk boiling conditions by using the average flow area $\left(A_{f}\right)$ between the bottom of the fixed header and the top of the modules:

$$
\frac{d z}{d t}=-\left(\frac{g \dot{m}_{g}}{\rho_{f} A_{f}}\right)=\left(\frac{g}{\rho_{f} A_{f}}\right)\left(\frac{d m_{f}}{d t}\right)
$$

Under boiling conditions, the rate of change in liquid mass inventory within a given module loop can be written as (making use of Eqs. (4), (7), and (8)):

$$
\frac{d m_{f}}{d t} \equiv-\dot{m}_{g}=\frac{Q_{T}}{h_{f g}-\left(m_{s} C_{p s}+m_{f} C_{p f}\right)\left(\frac{g}{A_{f}}\right)\left(\frac{d T_{s a t}}{d P}\right)}
$$

In Eq. (9) the change in saturation temperature with respect to system pressure is approximated by the Clausius-Clapeyron equation:

$$
\left(\frac{d T_{\text {sat }}}{d P}\right)=\frac{\rho_{f} \rho_{g} h_{f g}}{T_{f}\left(\rho_{f}-\rho_{g}\right)}
$$

To perform the transient EM analyses, deposited power decay curves were integrated over time to determine the total amount of heat released as a function of time. Figure 32 summarizes the decay curves used for the six composite lumped modules in the TRAC system model. For the purposes of this calculation, the deposited power curve for each module was used to calculate the deposited power as an adiabatic heat-up source. 


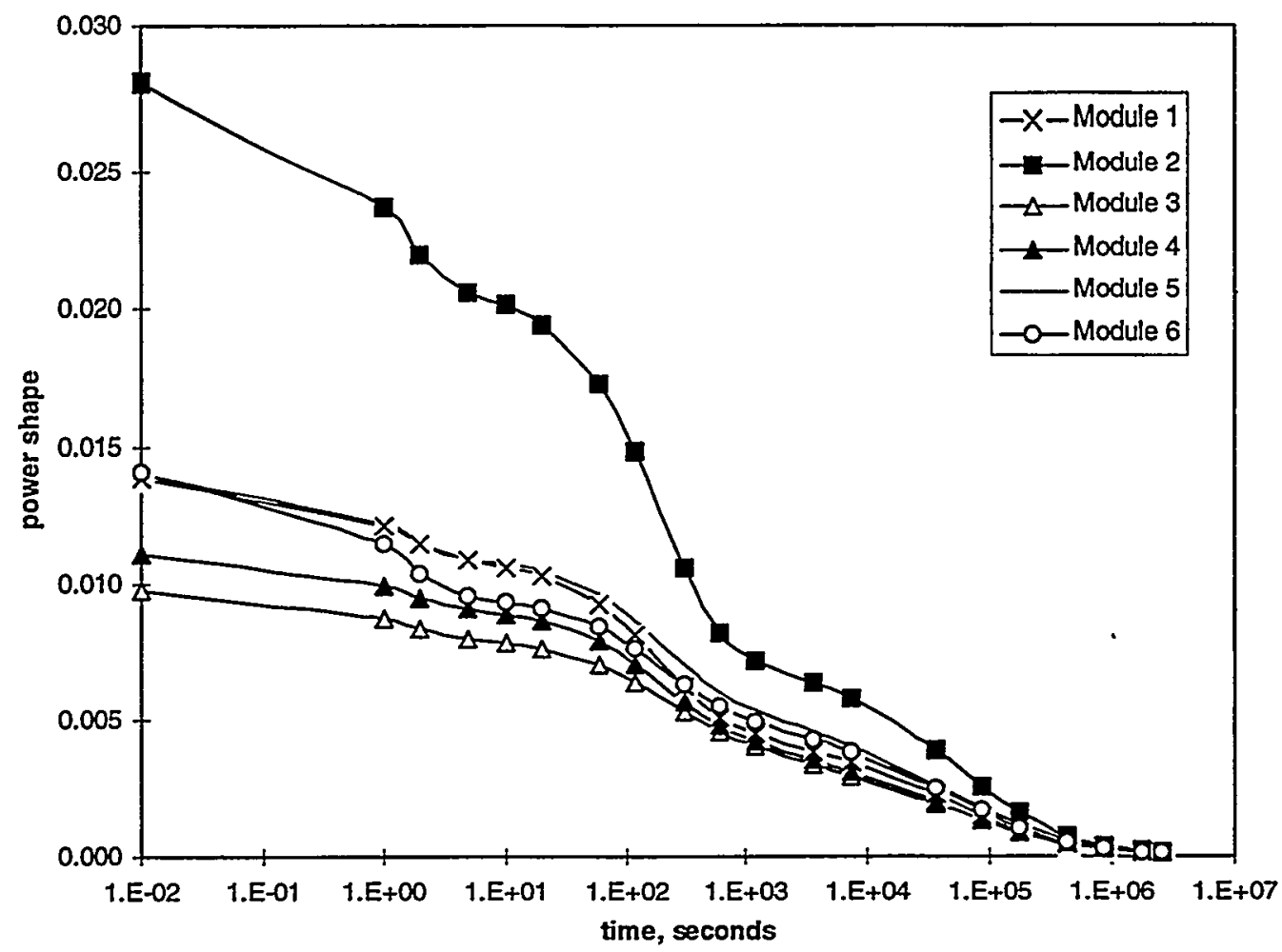

Figure 3-2 Deposited power profiles used in the TRAC system and EM models.

\section{Evaluation Model Results and Discussions}

Table 4-1 shows the results from the EM calculations for the six blanket modules. Module 1 was determined to be the worst case module that would uncover the quickest during an unmitigated LOCA scenario. Module 2, which has half the pre-incident deposited power, but a higher decay curve (see Fig. 3-2), is the only other module with a comparable dry-out time. Module 4, which also has a significant pre-incident deposited power, takes twice as long to reach dry-out and the other low power modules would take over four days to become uncovered.

Table 4-1 Times to reach boiling and initial dry-out for the six lumped blanket modules.

\begin{tabular}{|c|c|c|}
\hline Eumped & Timeto Reach & Time to Reach ho \\
Module & Boiling & Dry-out \\
(Hours) & (Hours) \\
\hline 1 & 3 & 28 \\
\hline 2 & 5 & 33 \\
\hline 3 & 11 & $>96$ \\
\hline 4 & 6 & 71 \\
\hline 5 & 23 & $>96$ \\
\hline 6 & 11 & $>96$ \\
\hline
\end{tabular}


Using $50 \mathrm{C}$ as the initial water temperature, the EM results show that Module 1 reaches the saturation temperature of $114 \mathrm{C}$ in approximately 3 hours at which point the onset of bulk boiling (OBB) is initiated. Beyond 3 hours into the transient, decay power levels are sufficiently low to preclude the potential for a counter-current-flow limitation [8]. Saturated bulk boiling occurs within the Module 1 flow channels where it is assumed that circulation is sufficient to bring the liquid water inventory to a nearly uniform temperature. In this situation no credit is taken for potential reflux of cooling water from condensation at the higher elevations within the piping network.

Once boiling occurs (i.e., at 3 hours into transient), the liquid level gradually drops until about 28 hours after the initiating event when the top of Module 1 is uncovered. As shown in Table 4-1, the lower power modules will take substantially longer to uncover. During the boiling phase, metal structure temperatures are assumed to follow the liquid saturation temperature corresponding to the system pressure. No liquid water inventory draining in from the HR, RHR, or pressurizer external piping is accounted for. Therefore, as water is boiled away, the static pressure within each module drops and its metal temperature slowly decreases. The thermal energy balance in the EM calculation accounts for the release of stored energy in the metal and in the remaining water inventory as the average temperature decreases.

The estimated coolant liquid level and maximum aluminum metal temperatures within Module 1 are shown in Figs. 4-1 and 4-2, respectively. For comparison purposes, the steady state and 10,000 hour exposure temperature limit criteria for aluminum are also shown in Fig. 4-2. As Fig. 4-2 indicates, aluminum temperatures remain below the 150 $\mathrm{C}$ limit throughout the early times of the event sequence and also below the $115 \mathrm{C}$ steady-state limit. At the point where the blanket modules begin to be uncovered, the estimated boil-off rate corresponds to about $0.25 \mathrm{gpm}$ of liquid water. Figure 4-3 shows estimated boil-off rate as a function of transient time, which is equivalent to the rate of reduction in the cooling water mass within Module 1.

Without corrective measures, it is anticipated that peak metal temperatures would begin to rise and exceed the design criteria beyond 28 hours after the initiation of the event. However, this time duration is sufficiently long that it is realistic to assume that additional measures can be implemented. Such measures include restoring the availability of the RHR system or cavity flood system, or replenishing liquid coolant inventory that is boiled away using, for example, purification lines. Initially about $0.25 \mathrm{gpm}$ would be required with demand decreasing as the residual deposited power decays. Beyond the EM calculations, preliminary FLOWTRAN-TF $[9,10]$ results indicate that acceptable metal temperatures are maintained for channels partially filled with water. However, at some reduced liquid level the onset of a thermal excursion is expected to occur. Further calculations will be required to quantify the point of thermal excursion.

In the above conservative EM calculations, credit was taken only for the safety class beam-shutdown system. The calculations indicate that margin exists at early times in the accident and, to prevent the loss of coolable geometry at later times, some sort of corrective measures must be taken within approximately the first day (i.e., an ultimate heat sink must be established). This time duration is sufficiently long that it is realistic to assume that additional administrative measures can be implemented, such as:

- Restoring the availability of the RHR system or cavity flood system, or

- Replenishing liquid coolant water inventory that is boiled-off using, for instance, purification lines. 


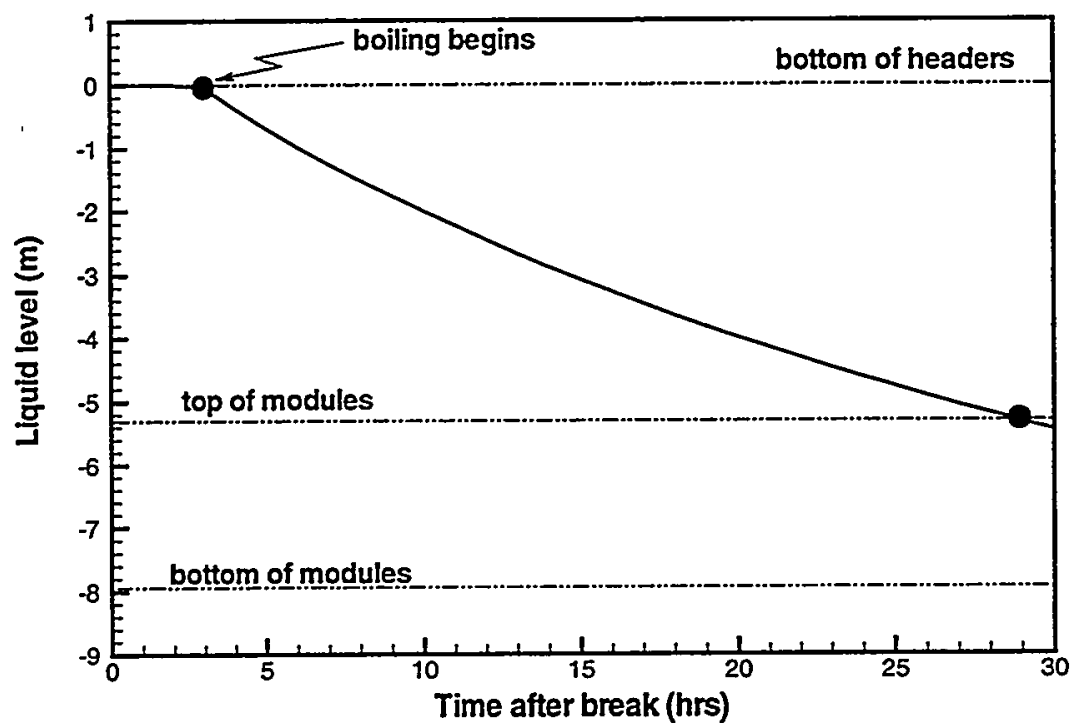

Figure 4-1 Module 1 estimated coolant liquid level as a function of time based on the EM.

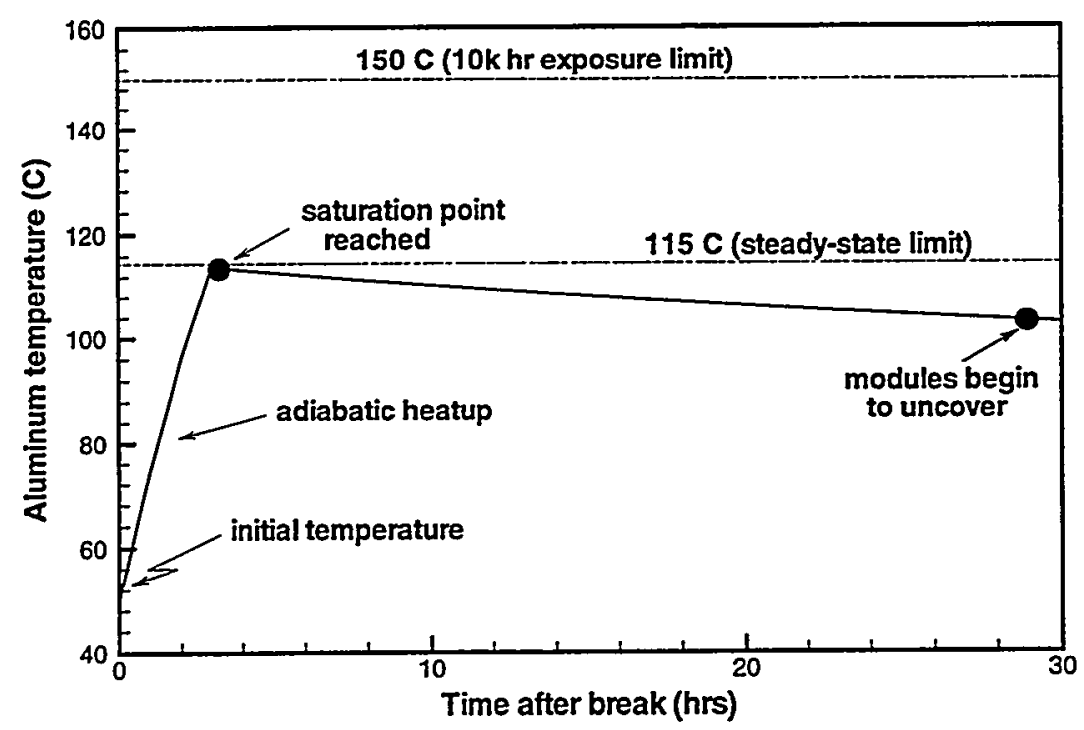

Figure 4-2 Module 1 estimated maximum aluminum temperature as a function of time based on the EM. 


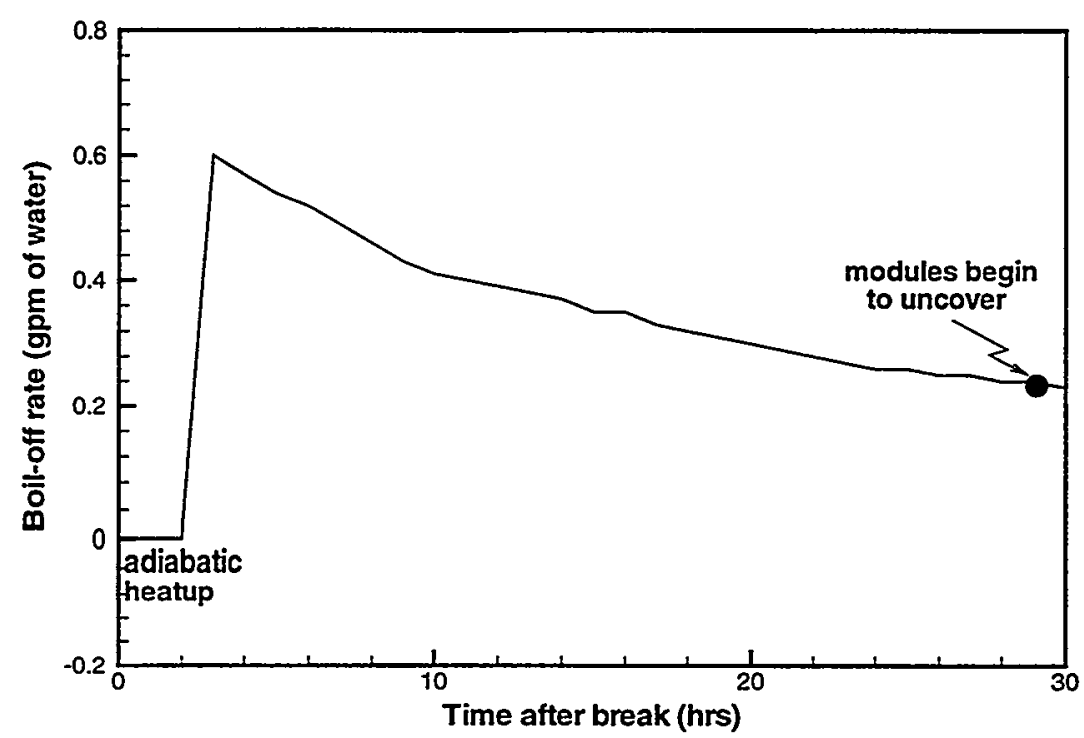

Figure 4-3 Module 1 estimated boil-off rate as a function of time based on the EM.

\section{Conclusions}

A conservative EM approach is used to analyze accident scenarios with significant coolant inventory losses during LBLOCAs external to the cavity vessel, where only the beam power is shut down and no other mitigation actions are taken. Prevention of the release of radioactive material to the environment is associated with maintaining a coolable blanket geometry throughout the event sequences. Without corrective actions the consequences for this event sequence are identical to those of Beyond Design Basis Accident (BDBA) event sequences (with beam shutdown only), where 52 rems and 0.16 rems would bound the maximum onsite and off-site consequences, respectively.

\subsection{Design Issues}

Material design criteria (steady state derived) are imposed to determine the maximum lead and aluminum (Series 6061 - Type T6) metal temperatures acceptable for the module components. The limiting values for these parameters are $327.5 \mathrm{C}$ and $115 \mathrm{C}$ for lead and aluminum, respectively. These material design criteria ensure that a coolable geometry can be maintained throughout the expected lifetime of each module unit. Less strict exposure dependent temperature limits can also be applied. Material limits for the plate-type structures have been tentatively set to $115 \mathrm{C}$ for steady-state normal operation (or indefinite times of exposure); and $150 \mathrm{C}$ for exposures less than 10,000 hours. Confidence bounds are required to establish the acceptable level of probability of exceeding these criteria. The results presented in this report represent conservative estimate values that should be bounding in nature. Quantification of overall uncertainties and their corresponding confidence levels (i.e., operating and 
modeling uncertainties) has not yet been performed. Future efforts to assess and confirm the bounding aspects of this EM will be performed.

Adequate safety margin is provided by the Reference 1 plate-type design to allow the APT blanket section to withstand the unmitigated LOCA scenario analyzed for a time period of over one day (28 hours). In particular, the maximum aluminum temperature remains below $115 \mathrm{C}$ during this time period. The maximum aluminum temperature is expected to eventually exceed $150 \mathrm{C}$ if the accident is allowed to proceed beyond this time frame.

\subsection{Predicted Impact}

Anticipated blanket conditions during LOCA Case 0 fall within all specified thermal/hydraulic design criteria for time periods of at least one day (28 hours). During this time no onsite or off-site impact to people or the environment would occur from conditions within the blanket region of the APT as a result of this LBLOCA. Beyond one day, metal temperatures within the blanket module will slowly increase and can exceed the limits imposed to ensure structural integrity. If this is allowed to occur slumping of the blanket plates can damage the helium tubes and target ladders leading to the potential release of hazardous and radioactive materials that could adversely impact.the environment. However, the analysis presented in this report shows that a minimum of 28 hours are available in which to take additional action to mitigate the accident event and prevent undesirable consequences. 


\section{References}

1 L. L. Hamm, S. Y. Lee, M. A. Shadday, and F. G. Smith, III, "APT Blanket System Safety Analysis Methodology," Westinghouse Savannah River Company, WSRCTR-98-0052 (May 1998).

2 L. L. Hamm, S. Y. Lee, M. A. Shadday, and F. G. Smith, III, "APT Blanket System Loss-of-Coolant Accident (LOCA) Analysis Based on Initial Conceptual Design Case 1: External HR Break Near Inlet Header," Westinghouse Savannah River Company, WSRC-TR-98-0059 (July 1998).

3 L. L. Hamm, S. Y. Lee, M. A. Shadday, and F. G. Smith, III, "APT Blanket System Losș-of-Coolant Accident (LOCA) Analysis Based on Initial Conceptual Design Case 2: External HR Break at Pump Outlet with Pump Trip," Westinghouse Savannah River Company, WSRC-TR-98-0060 (July 1998).

4 L. L. Hamm, S. Y. Lee, M. A. Shadday, and F. G. Smith, III, "APT Blanket System Loss-of-Coolant Accident (LOCA) Analysis Based on Initial Conceptual Design Case 3: External HR Break at Pump Outlet without Pump Trip," Westinghouse Savannah River Company, WSRC-TR-98-0061 (July 1998).

5 L. L. Hamm, S. Y. Lee, M. A. Shadday, and F. G. Smith, III, “APT Blanket System Loss-of-Coolant Accident (LOCA) Analysis Based on Initial Conceptual Design Case 4: External Pressurizer Surge Line Breaker Near Inlet Header," Westinghouse Savannah River Company, WSRC-TR-98-0062 (July 1998).

6 L. L. Hamm, S. Y. Lee, M. A. Shadday, and F. G. Smith, III, "APT Blanket System Loss-of-Coolant Accident (LOCA) Analysis Based on Initial Conceptual Design Case 5: External RHR Break Near Inlet Header," Westinghouse Savannah River Company, WSRC-TR-98-0063 (July 1998).

7 L. L. Hamm, S. Y. Lee, M. A. Shadday, and F. G. Smith, III, "APT Blanket System Model Based On Initial Conceptual Design - Integrated 1D TRAC System Model," Westinghouse Savannah River Company, WSRC-TR-98-0053 (July 1998).

8 S. Y. Lee and L. L. Hamm, "APT Blanket Safety Analysis: Counter Current Flow Limitation for Cavity Spaces," Westinghouse Savannah River Company, WSRCTR-98-0086 (July 1998).

9 L. L. Hamm, S. Y. Lee, M. A. Shadday, and F. G. Smith, III, "APT Blanket Detailed Bin Model Based on Initial Plate-Type Design - 3-D FLOWTRAN-TF Model," Westinghouse Savannah River Company, WSRC-TR-98-0055 (July 1998).

10 L. L. Hamm, S. Y. Lee, M. A. Shadday, and F. G. Smith, III, "FLOWTRAN-TF Code Modifications made for APT Blanket Safety Analyses," Westinghouse Savannah River Company, WSRC-TR-98-0056 (July 1998).

11 TECPLOT (Version 7): Productive Power for Data Visualization, User's Manual, 1996, Amtec Engineering, Inc., P.O. Box 3633, Bellevue, WA 98009-3633. 


\section{Appendix A: Software Specifications for BOIL Code}

Requirements of the BOIL code (see Appendix C) are defined below. The BOIL code was developed to analyze accident scenarios with significant coolant inventory losses during LBLOCAs external to the cavity vessel.

The BOIL code computes transient liquid level and maximum aluminum temperatures whose output results are converted to a form that is TECPLOT'TM-ready. TECPLOT'TM (1996) is a commercially available interactive graphics tool outside the domain of this report (see Ref. [11] for further details on TECPLOT ${ }^{\mathrm{MM}}$.

\section{Function:}

The functional requirements placed on BOIL are as follows:

1) Capability to simulate saturated transient boil-off of water inventory using a conservative lumped approach. The governing equations consider the situations for adiabatic heat-up (non-boiling) and boil-off based on the assumptions of thermal equilibrium.

2) Capability to impose prescribed initial decay power, prescribed level of initial liquid inventory, and transient decay heat fractions.

3) Capability to write code results to output in a form which can readily be made usable by standard graphics software such as TECPLOTTM.

Acceptance criterion: Documentation of test case results in graphical form using TECPLOT'M or other graphics software.

\section{Performance and attributes:}

1) A UNIX based executable that has the capability to run on the following computer platforms:

Computer platform A:

$\begin{array}{ll}\text { Platform: } & \text { SGI Indigo 2 (R10000) } \\ \text { System: } & \text { IRIX } 6.2 \\ \text { Compilers: } & \text { f77 v7.1 } \\ \text { Options: } & \text {-O for FFLAGS }\end{array}$

Computer platform B:

Platform: SGI Indy (R5000)

System: $\quad$ IRIX 5.3

Compilers: $\quad 177$ v7.1;

Options: $\quad-O$ for FFLAGS;

Acceptance criterion: Successful installation testing using simple analytic solutions and MicroSoft EXCEL ${ }^{\mathrm{TM}}$ spread sheet results, syntax error checking using FTNCHEK (a UNIX utility feature for checking fortran coding), and spot checking calculations within a computer run through the UNIX debug facility.

Design constraints imposed on design and implementation activities:

None 


\section{External interfaces}

1) Capability for BOIL to write its results to output in an ascii form that can readily be made usable by standard graphics software such as TECPLOT'M version 7.

\section{Coding standards:}

1) UNIX version SGI fortran $f 77$ compiler compatible under the IRIX operating system.

Acceptance criterion: Successful installation testing.

2) A modular code structure that minimizes the time and effort required to perform maintance and upgrades to its algorithms.

Acceptance criterion: Well commented subroutines having a uniform coding style.

\section{Designation of responsibilities:}

Owner (and code proprietor): Tester(s):
S. Y. Lee

F. G. Smith, III, and S. Y. Lee

\section{Software Testing:}

The BOIL code was tested on a lumped energy balance problem under transient condition using a Microsoft EXCEL ${ }^{\mathrm{TM}}$ spreadsheet. The test problems were also selected based on the fact that analytical solutions exists that definitively establishes BOIL's accuracy capability and the resulting impact that time step size parameter setting has on accuracy. Verification was made through comparison of generated output results published in the analysis report to analytic solutions.

The BOIL code was compiled on the following computer hardware and software settings:

\section{Computer platform:}

Platform: $\quad$ SGI Indigo 2 (R10000)

System: $\quad$ IRIX 6.2

Compilers: $\quad f 77$ v7.1

Options: $\quad-O$ for FFLAGS

The executable file generated (boil) was then stored for later simulation tests performed on the same computer platform as specified above.

An input deck consistent with those described in Appendix B was generated. For each BOIL test run, its output files were stored for viewing. The graphics output files were processed and viewed interactively within TECPLOT ${ }^{\mathrm{TM}}$ (version 7). Key results for the test problem are presented in Section 4. From the above executions (the standard output files from BOIL and the graphics output visually shown in TECPLOT ${ }^{\mathrm{TM}}$ ), selective liquid level and temperature solutions, along with integrated decay heat during LOCA transient period, were cross verified with the tabulated values. The input deck, output files, source coding, and executables are stored under SRTC's AFS system. The official version of the above files reside on the UNIX AFS system located in the directory: 


\section{Appendix B: Sample Input Deck}

A sample-input file for the BOIL code (see Appendix $\mathrm{C}$ ) is provided below. The input file applies to an external LBLOCA with beam shutdown only (i.e., no other migitative systems were activated).

Input file data.in

\begin{tabular}{|c|c|c|c|c|c|}
\hline $\bmod$ & zo & $\operatorname{amf} \quad d t$ & & nd & tstrt \\
\hline \multirow[t]{3}{*}{1} & 6.608 & 0.398 & 0.50 & 345600.0 & 950.0 \\
\hline & zmo & farea & $w m^{*} c p$ & go & to \\
\hline & 1.379 & 0.405 & $6.805 \mathrm{e} 5$ & $2.37 e 7$ & 323.15 \\
\hline $\bmod$ & zo & $\operatorname{amf}$ & $d t$ & tend & tstrt \\
\hline \multirow[t]{3}{*}{2} & 6.944 & 0.432 & 0.50 & 345600.0 & 950.0 \\
\hline & zmo & farea & $w^{*} \mathrm{cp}$ & qo & to \\
\hline & 1.750 & 0.319 & $4.079 \mathrm{e} 6$ & $1.07 \mathrm{e} 7$ & 323.15 \\
\hline $\bmod$ & zo & $\operatorname{amf}$ & dt & tend & tstrt \\
\hline \multirow[t]{3}{*}{3} & 6.608 & 0.04575 & 0.50 & 345600.0 & 950.0 \\
\hline & zmo & farea & $w m^{\star} c p$ & qo & to \\
\hline & 1.379 & 0.217 & $3.839 \mathrm{e} 5$ & $3.56 \mathrm{e} 6$ & 323.15 \\
\hline $\bmod$ & zo & $\operatorname{amf}$ & at & tend & tstrt \\
\hline \multirow[t]{3}{*}{4} & 6.952 & 0.106 & 0.50 & 345600.0 & 950.0 \\
\hline & zmo & farea & $w m * c p$ & qo & to \\
\hline & 1.750 & 0.245 & $2.431 \mathrm{e} 6$ & $9.34 e^{6}$ & 323.15 \\
\hline $\bmod$ & zo & $a m f$ & dt & tend & tstrt \\
\hline \multirow[t]{3}{*}{5} & 6.960 & 0.109 & 0.50 & 345600.0 & 950.0 \\
\hline & zmo & farea & $w m * c p$ & qo & to \\
\hline & 1.750 & 0.258 & $3.875 \mathrm{e} 6$ & $3.17 e 6$ & 323.15 \\
\hline mod & zo & amf & $d t$ & tend & tstrt \\
\hline \multirow[t]{3}{*}{6} & 8.196 & 0.310 & 0.50 & 345600.0 & 950.0 \\
\hline & zmo & farea & $w m * c p$ & qo & to \\
\hline & 0.10 & 0.310 & $4.609 e 5$ & $5.71 e 6$ & 323.15 \\
\hline
\end{tabular}


WESTINGHOUSE SAVANNAH RIVER COMPANY

BLANKET MODULE BOIL-OFF TIMES DURING A LOCA (CASE O: WITH BEAM SHUTDOWN ONLY)
Report:

Section:

Date:

Page:
WSRC-TR-98-00213

Appendix B

$08 / 12 / 98$

B2 of 2

(This Page Intentionally Left Blank) 


\section{Appendix C: Code Listing}

A code listing of the fortran program BOIL and its associated fortran subroutines is presented below. An algorithm description is provided at the front of each routine. The following is a listing of the routines:

- boil.f - main program that reads in the input and writes out the output.

- hfgsat.f - computes latent heat of light water.

- rhofs.f - computes fluid saturation density.

- tsat.f - computes saturation temperature at system pressure.

\section{Main program boil.f}

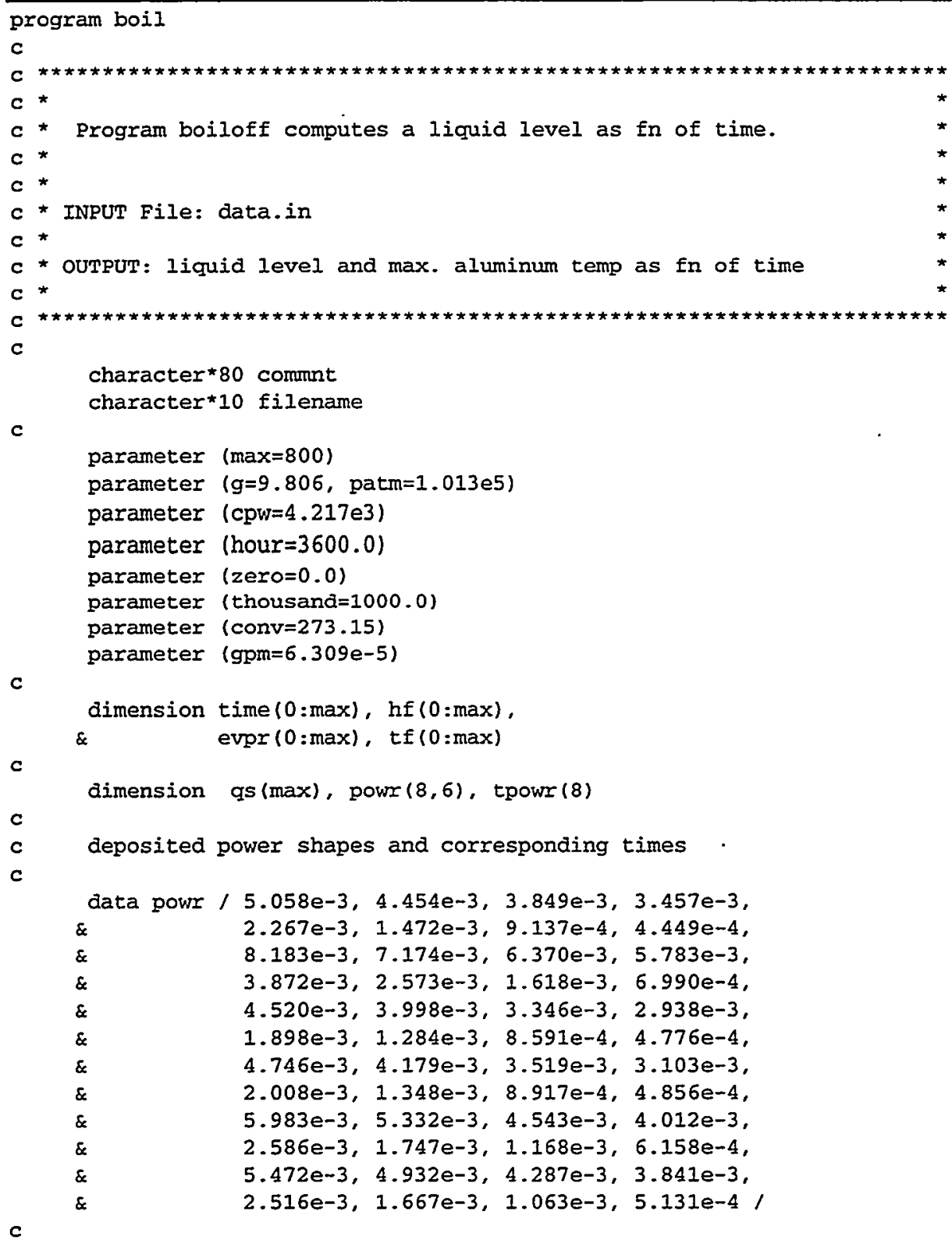


WESTINGHOUSE SAVANNAH RIVER COMPANY

Report: WSRC-TR-98-00213

BLANKET MODULE BOIL-OFF TIMES DURING A LOCA

Section:

Appendix $\mathrm{C}$

(CASE 0: WITH BEAM SHUTDOWN ONLY)

Date:

$08 / 12 / 98$

Page:

$\mathrm{C} 2$ of 6

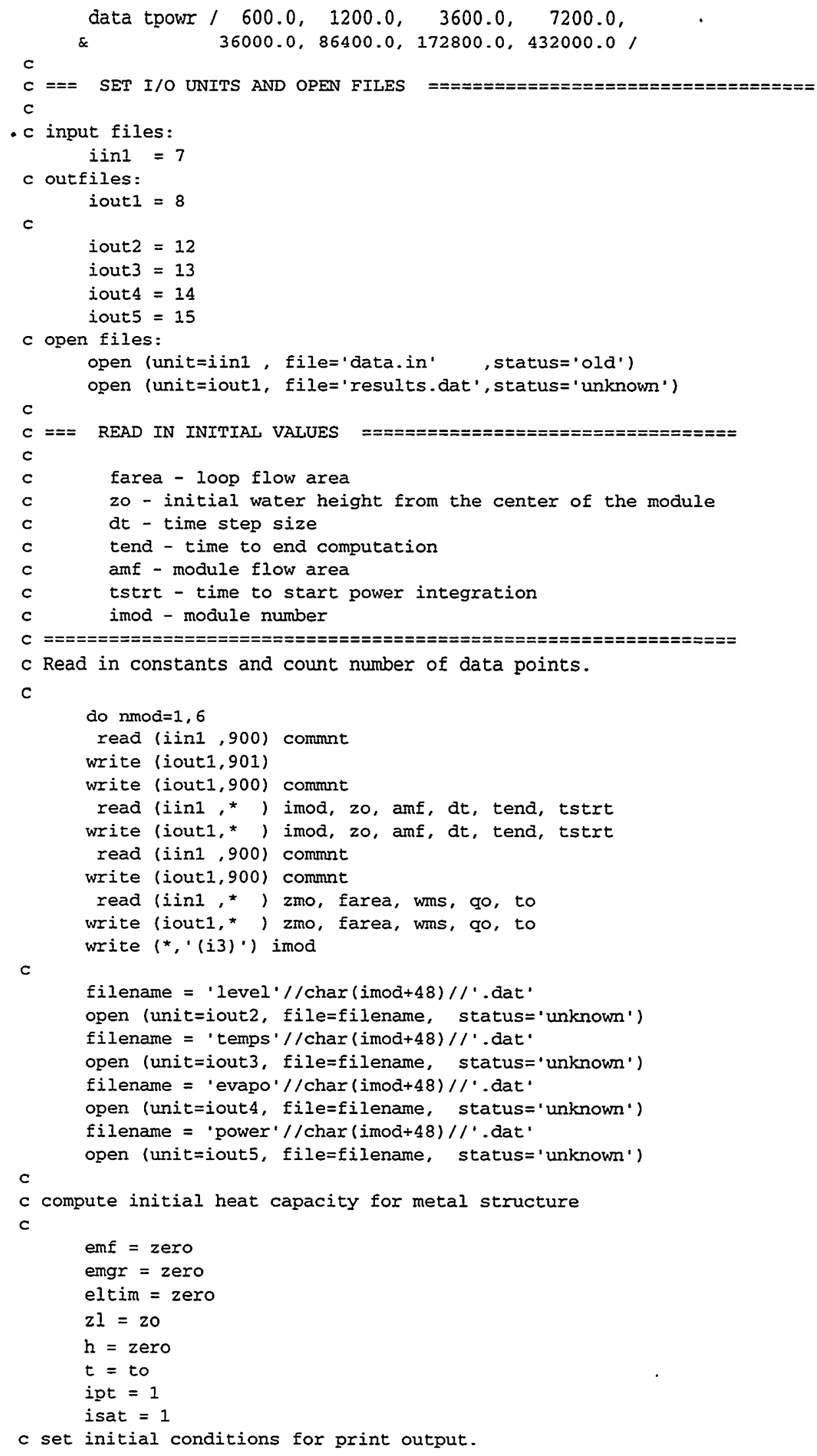


time $(0)=$ zero

$\mathrm{hf}(0)=$ zero

$t f(0)=$ to

c compute initial pressure corresponding to initial liquid level.

call rhofs ( $t$, rhof)

po $=$ patm + rhof* $g * z$

c update thermodynamic properties at initial pressure.

call tsat (po,ts,dtsdp)

c compute liquid mass

wmf $=2.0 *$ rhof*amf* $z \mathrm{mo}^{*} \mathrm{cpw}$

wloop $=$ rhof ${ }^{\star}$ farea $*(z l-z m o){ }^{*} \mathrm{Cpw}$

c compute total fluid and structure mass initially. wmfs $=$ wms + wmf + wloop

$c$ print initial values for the present analysis. write (iout 1,902 ) t-conv, ts-conv

write (iout 1,903$)$ po

c

write (iout1,904) zo - zmo

$c$ nt is the number of time steps.

c

nt $=$ int (tend/dt)

nfreq $=$ int (hour/dt)

qsum $=$ zero

do 100 it $=1, n t$

eltim $=$ eltim+dt

ptime $=$ tstrt + eltim

c

c compute decay power at each time

c

if (ptime.le.tpowr(1)) then

decay $=$ powr $(1$, imod $)$

else if (ptime.ge.tpowr (8)) then

decay $=$ powr $(8$, imod $)$

else

do $k=2,8$

if (ptime.1t.tpowr $(k)$ ) then

frc $=($ ptime - tpowr $(k-1)) /($ tpowr $(k)-\operatorname{tpowr}(k-1))$

$\&$

decay $=$ powr $(k-1$, inod $)$

goto 10

$+\operatorname{frc}($ powr $(k, i m o d)-\operatorname{powr}(k-1, i m o d))$

end if

end do

end if

10 qd1 $=$ qo*decay

if $($ it.gt.1) qsum $=$ gsum $+(q d-q d 1) * d t$

$q d=q d I$

c compute temperature when fluid is subcooled or boiled.

if ((t.1t.ts) .and. (isat.eq.1)) then

$t=t+q d \star d t /$ wmfs

else

c fluid is saturated corresponding to the system pressure.

$c$ ts is the saturated temperature corresponding to system pressure.

isat $=2$

$p=$ patm + rhof* $g^{\star} z 1$

call tsat (p,ts, atsop)

call rhofs (ts, rhof)

call hfgsat (ts,hfgs)

denom $=$ hfgs $-g^{\star}$ wmfs*dtsdp/farea 
WESTINGHOUSE SAVANNAH RIVER COMPANY

BLANKET MODULE BOIL-OFF TIMES DURING A LOCA (CASE 0: WITH BEAM SHUTDOWN ONLY)
Report: WSRC-TR-98-00213

Section:

Date:

Page:
Appendix C

08/12/98

$\mathrm{C} 4$ of 6

$c$

emfn $=e m f-q d^{*} d t /$ denom

$d z=($ emfn - emf $) /($ rhof*farea $)$

$z l=z l+d z$

wloop $=$ rhof*farea* $(z l-z m o) * c p w$

wmfs $=\mathrm{wms}+\mathrm{wmf}+\mathrm{wloop}$

$t=t s$

$h=z l-z o$

engr $=(e m f-e m f n) /\left(d t^{*}\right.$ rhof $)$

endif

emf $=$ emfn

if (ipt .eq. nfreq) then

tmhr = eltim/hour

c

iit = it/nfreg

time $(i i t)=t m h r$

$t f(i i t)=t$

$h f(i i t)=h$

evpr(iit) = emg $x$

c qs $(i i t)=$ qsum

$$
\begin{aligned}
\text { ipt } & =1 \\
\text { else } & \\
\text { ipt } & =i p t+1
\end{aligned}
$$

end if

100 continue

c

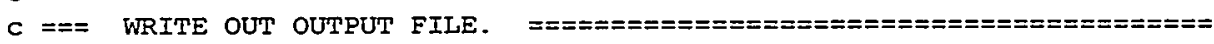
write (iout2,99)

99 format ('VARIABIES = time, level')

C

do $i=1, i i t+1$

write (iout2, $(2 f 11.2) \cdot)$ time $(i-1), h f(i-1)$

enddo

c

write (iout3, 199)

199

format ('VARIABIES = time, temp')

do $i=1, i i t+1$

write(iout $3, \cdot(2 f 11.2)$ ') time $(i-1), t f(i-1)-c o n v$ enddo

c

write (iout4, 299)

299 format ("VARIABLES = time, evaporation in gpm") do $i=1, i i t+1$

write (iout $\left.4, \cdot(2 f 11.2)^{\prime}\right)$ time $(i-1)$, evpr $(i-1) / g p m$ enddo

c

write (iout5,399)

399 format ('VARIABLES = time, power')

do $i=1$, it

write(iout5, ' $\left.(2 f 11.2)^{\prime}\right)$ time(i), gs (i)/thousand endao

c

close (iout2)

close (iout3)

close (iout 4 )

close (iout5)

end do

c

900 format $(280)$

901 format (' $=======$ The following are the input parameters $======$ ')

902 format ('Initial temp $=$ ',f6.2, ' C',' Initial sat temp = ', 
WESTINGHOUSE SAVANNAH RIVER COMPANY

BLANKET MODULE BOIL-OFF TIMES DURING A LOCA

(CASE 0: WITH BEAM SHUTDOWN ONLY)
Report: WSRC-TR-98-00213

Section: Appendix C

Date:

Page:

$\left.\& f 6.2,{ }^{\prime} C^{\prime}\right)$

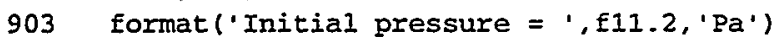

904 format ('Initial liquid level above the top of the module = ', $\& f 7.2, ' m \cdot)$

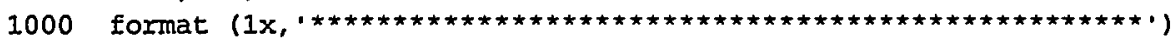

c
stop

end

\section{Subroutine hfgsat.f}

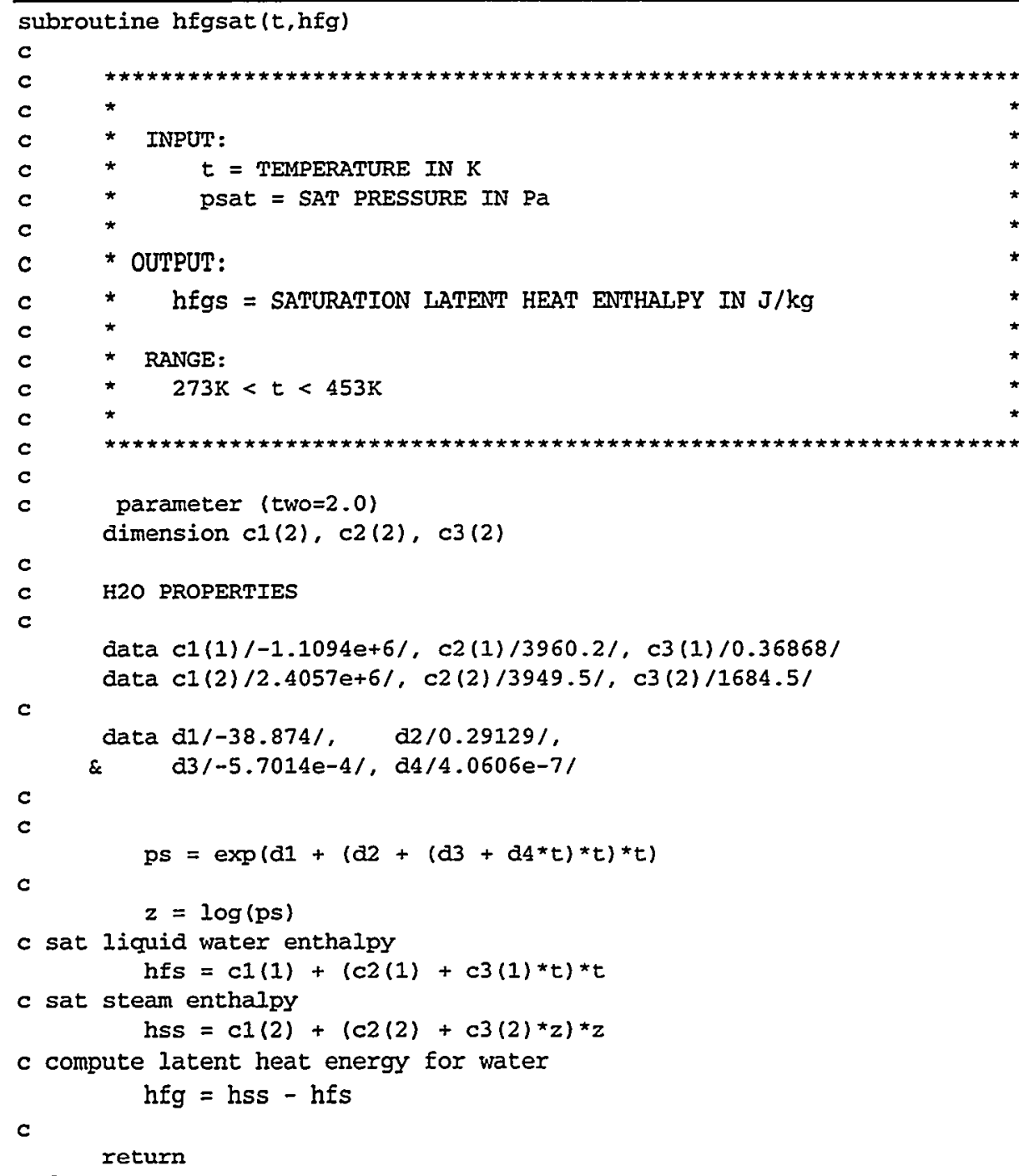

\section{Subroutine rhofs.f}

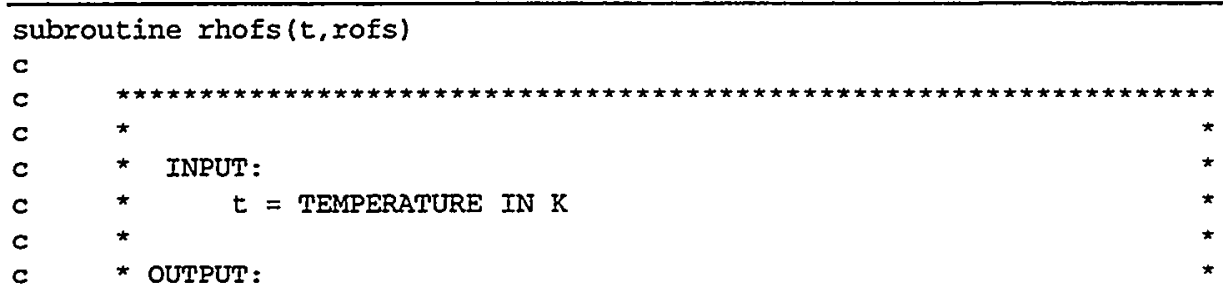


WESTINGHOUSE SAVANNAH RIVER COMPANY

BLANKET MODULE BOIL-OFF TIMES DURING A LOCA (CASE O: WITH BEAM SHUTDOWN ONLY)
Report: WSRC-TR-98-00213

Section:

Date:

Page:
Appendix C $08 / 12 / 98$

C6 of 6

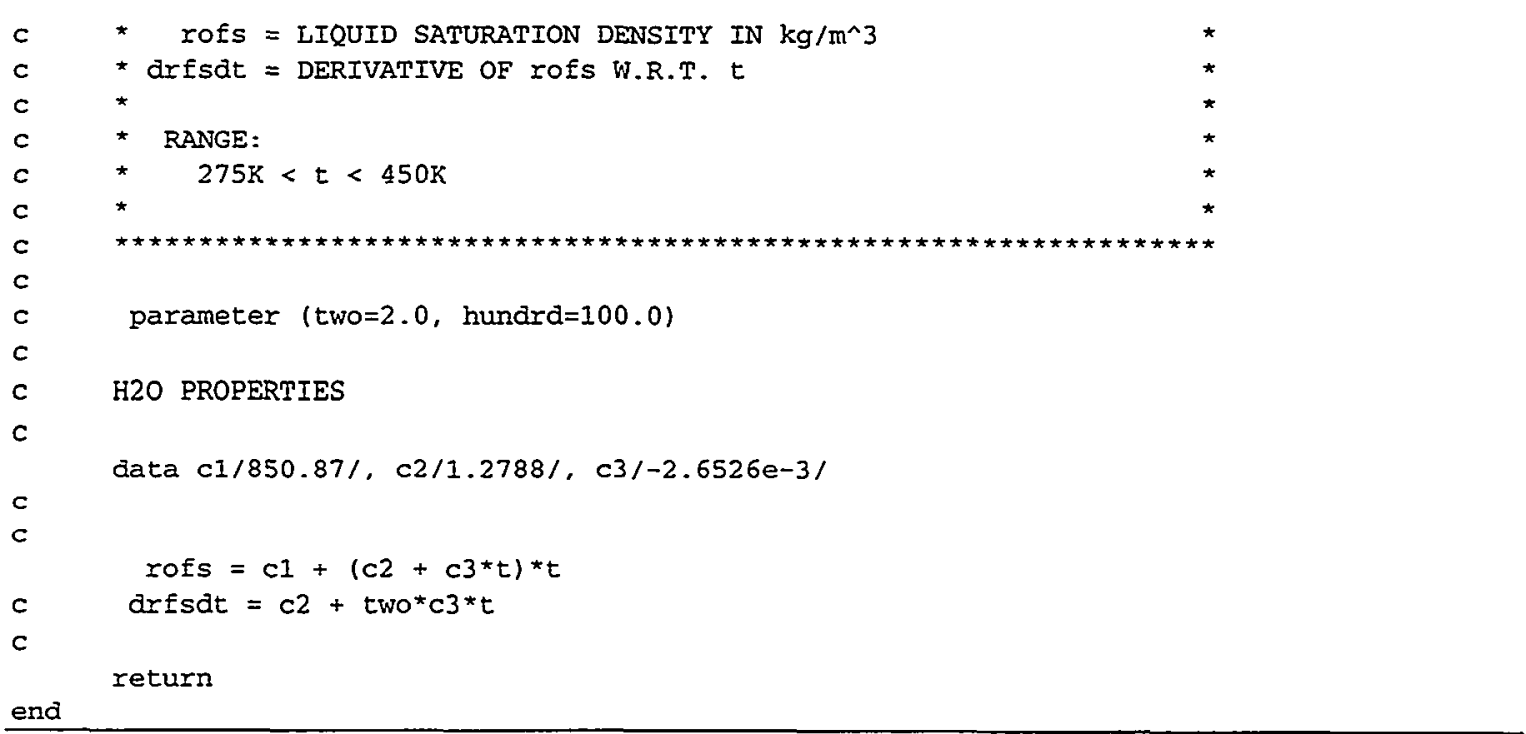

\section{Subroutine tsat.f}

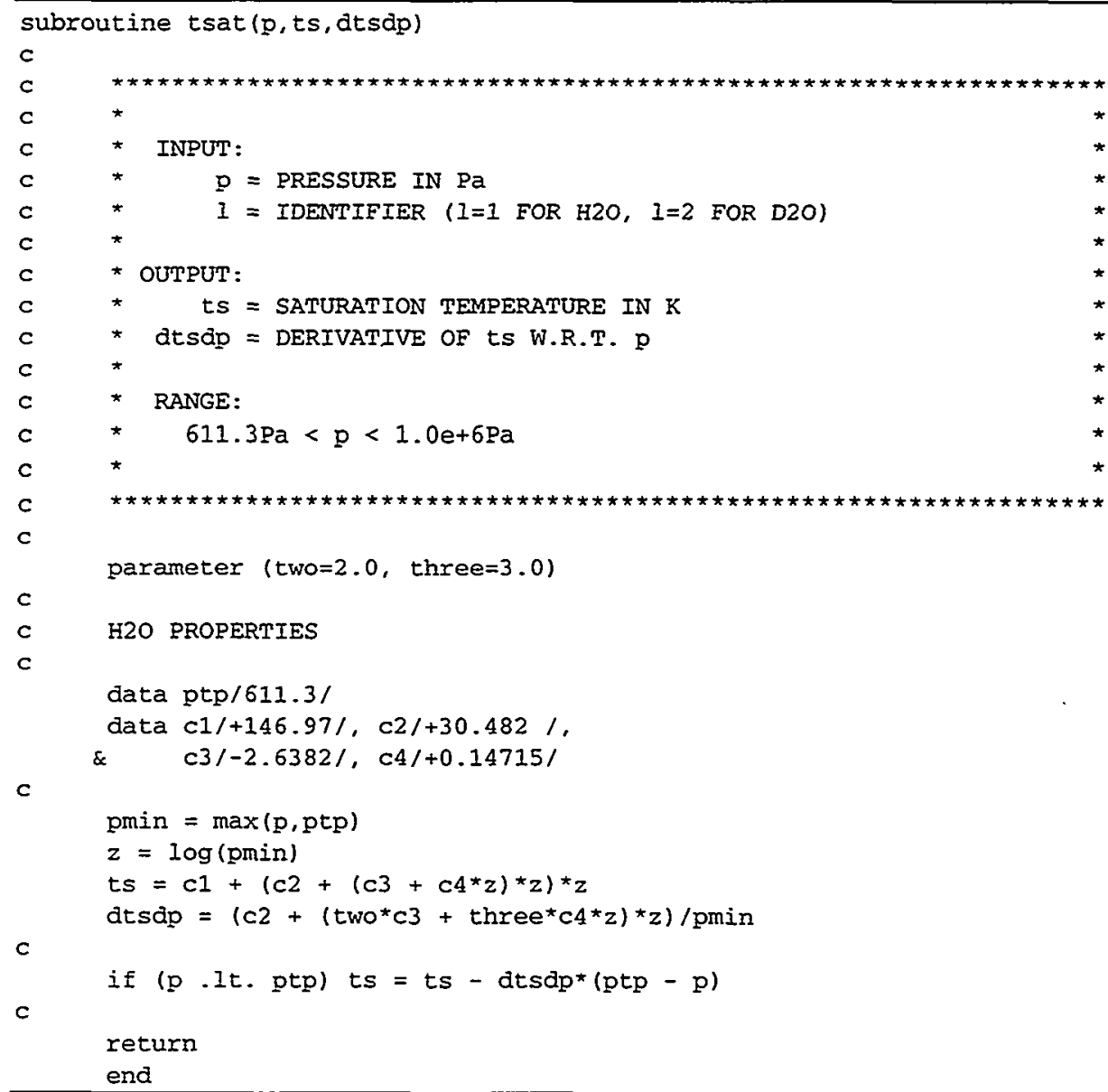

